\title{
Establishment of a genetically engineered chicken DF-1 cell line for efficient amplification of influenza viruses in the absence of trypsin
}

Kelly Chungu, Young Hyun Park, Seung Je Woo, Su Bin Lee, Deivendran Rengaraj, Hong Jo Lee and Jae Yong $\operatorname{Han}^{*}$ (D)

\begin{abstract}
Background: The initial step of influenza infection is binding of the virus to specific sialic acid receptors expressed by host cells. This is followed by cell entry via endocytosis. Cleavage of the influenza virus hemagglutinin (HA) protein is critical for infection; this is performed by host cell proteases during viral replication. In cell culture systems, HA is cleaved by trypsin added to the culture medium. The vast majority of established cell lines are mammalian.

Results: In the present study, we generated genetically engineered chicken DF-1 cell lines overexpressing transmembrane protease, serine 2 (TMPRSS2, which cleaves HA), ST3 beta-galactoside alpha-2,3-sialyltransferase 1 (ST3GAL1, which plays a role in synthesis of $a-2,3$ linked sialic acids to which avian-adapted viruses bind preferentially), or both. We found that overexpression of TMPRSS2 supports the virus life cycle by cleaving HA. Furthermore, we found that overexpression of ST3GAL1 increased the viral titer. Finally, we showed that overexpression of both TMPRSS2 and ST3GAL1 increased the final viral titer due to enhanced support of viral replication and prolonged viability of the cells. In addition, overexpression of these genes of interest had no effect on cell proliferation and viability.

Conclusions: Taken together, the results indicate that these engineered cells could be used as a cell-based system to propagate influenza virus efficiently in the absence of trypsin. Further studies on influenza virus interactions with chicken cell host factors could be studied without the effect of trypsin on cells.
\end{abstract}

Keywords: Avian influenza virus, Chicken, DF-1 cell, Proteases, Sialic acid

\footnotetext{
*Correspondence: jaehan@snu.ac.kr

Department of Agricultural Biotechnology and Research Institute of Agriculture and Life Sciences, College of Agriculture and Life Sciences, Seoul National University, Seoul 08826, Korea
}

C C The Author(s). 2021 Open Access This article is licensed under a Creative Commons Attribution 4.0 International License, which permits use, sharing, adaptation, distribution and reproduction in any medium or format, as long as you give appropriate credit to the original author(s) and the source, provide a link to the Creative Commons licence, and indicate if changes were made. The images or other third party material in this article are included in the article's Creative Commons licence, unless indicated otherwise in a credit line to the material. If material is not included in the article's Creative Commons licence and your intended use is not permitted by statutory regulation or exceeds the permitted use, you will need to obtain permission directly from the copyright holder. To view a copy of this licence, visit http://creativecommons.org/licenses/by/4.0/. The Creative Commons Public Domain Dedication waiver (http://creativecommons.org/publicdomain/zero/1.0/) applies to the data made available in this article, unless otherwise stated in a credit line to the data. 


\section{Background}

The influenza virus surface protein hemagglutinin (HA) plays two major roles during the early life cycle of the virus: it binds to cell surface receptors and facilitates fusion of viral and endosomal membranes to release viral RNA (vRNA) into the cytoplasm [1]. The HA protein is translated as an uncleaved HAO precursor protein; it is folded as a trimer that is both glycosylated and acylated. Because uncleaved HAO is unable to initiate membrane fusion, lack of cleavage means no infection $[2,3]$. Therefore, cleavage of HA0 into HA1 and HA2 subunits is critical for membrane fusion with the endosome and subsequent release of viral segments into the cytoplasm prior to nuclear transport, transcription, and replication. Highly pathogenic avian influenza (HPAI) viruses harbor a polybasic amino acid sequence at the cleavage site, which is cleaved endogenously by ubiquitously expressed subtilisin-like proteases such as furin and proprotein convertases with polybasic specificity, resulting in fatal systemic infection [4-7]. By contrast, low pathogenic avian influenza (LPAI) viruses are cleaved by trypsin-like proteases such as miniplasmin, tryptase Clara, Mast cell tryptase, type II transmembrane serine proteases such as TMPRSS2 and TMPRSS4, and human airway trypsinlike protease (HAT) [8-10]. However, recent studies show that Madin-Darby canine kidney (MDCK) cell lines expressing proteolytic enzymes such as TMPRSS2, $\mathrm{HAT}$, and Mosaic serine protease large form cleave HA in the absence of trypsin $[1,11]$.

Influenza viruses are propagated for vaccine production and for studies of the viral life cycle, interactions with host cellular factors, and host immune responses. Egg-based and cell-based systems are used to generate influenza vaccines. However, viruses produced in eggs often harbor undesired mutations in HA that render the vaccine less effective. In addition, some reassorted viral strains grow poorly, and highly pathogenic strains are difficult to propagate, in eggs. Other drawbacks of egg-based systems include limited flexibility for expanded vaccine manufacture and interruption of vaccine production/quality during disease outbreaks in poultry $[12,13]$.

Cell culture-based propagation of influenza virus is an alternative system that offers various advantages, including easy scale-up for cell engineering systems, increased vaccine purity, and utility for people with allergies to egg proteins [14]. However, propagation of LPAI viruses in cell-based culture systems requires supplementation with trypsin to cleave the HA protein and drive viral replication [15]. In some cell lines, high trypsin concentration showed also variation in the resulting yield of virus, thus requiring optimization [16]. This may be overcome by removing the reliance on exogenous trypsin. In addition, removing trypsin will reduce the costs of production. Moreover, using species specific cell lines will remove the need of viruses to adapt to host cells $[16,17]$.

Avian derived cell lines such as chicken DF-1 cells can be used to propagate influenza viruses because they express $\alpha$-2,3-linked sialic acid receptors, which are targeted preferentially by avian-adapted viruses [18]; also, immortalized cell lines provide a suitable platform for generating stable cell lines that can be used for virus propagation. Engineering cells such that they can support faster viral replication will also be a great advantage to the vaccine industry.

Here, we developed genetically engineered chicken DF-1 cells that stably overexpress ST3 beta-galactoside alpha-2,3-sialyltransferase 1 (ST3GAL1), which catalyzes transfer of the sialic acid Neu5Ac from CMP-Neu5Ac to Gal $31,3 \mathrm{GalNac}$ on glycoproteins or glycolipids with an $\alpha-2,3$ linkage. We also developed a cell line overexpressing type II transmembrane protease, serine 2 (TMPR SS2), which is required for cleavage of HA. Finally, we developed a cell line expressing both ST3GAL1 and TMPRSS2. The engineered cell lines allowed efficient propagation of influenza virus in the absence of exogenous trypsin. These engineered cells may provide a platform for viral amplification even in the absence of trypsin, thereby allowing development of vaccine for poultry and study of virus replication in avian cells.

\section{Results}

Establishment of TMPRSS2- and TMPRSS4-overexpressing cell lines and subsequent viral challenge

The presence of trypsin-like proteases that cleave HA means that influenza viruses preferentially infect the respiratory and gastrointestinal tracts. Therefore, we compared the distribution of TMPRSS 2 and TMPRSS4 in lung, trachea, liver, small intestine, and large intestine samples from WL chickens aged 18 weeks and wild-type (WT) DF-1 cells by quantitative real-time PCR (qRTPCR). We found that compared with WT DF-1 cells, TMPRSS2 was expressed at high levels in liver, large intestine, and lung, whereas TMPRSS4 was expressed only in liver and trachea (Fig. 1a). The low expression of TMPRSS2 and TMPRSS4 by WT DF-1 cells suggests that they would not support viral replication efficiently.

Therefore, we constructed a piggyBac transposon vector that contained the protein coding region for either chicken TMPRSS2 or TMPRSS4 (Fig. 1b). This was used to drive overexpression in DF-1 cells. We then measured the effects on cell viability and proliferation of influenza virus. Firstly, we analyzed expression of mRNA in genetically engineered cells. The qRT-PCR results showed that overexpression of TMPRSS2 mRNA in TMPRSS2 overexpressing (O/E-T2) cells was 350-fold higher than that in WT DF-1 cells, whereas expression of TMPRSS4 
(a)
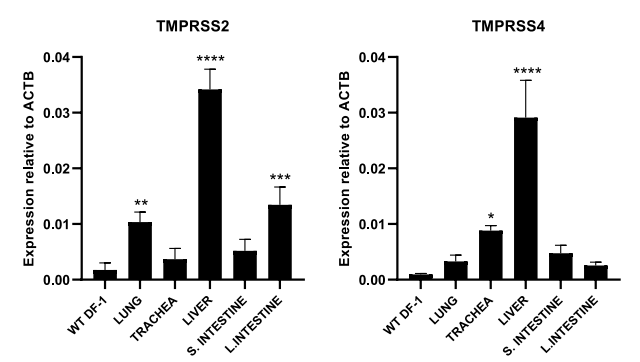

(c)

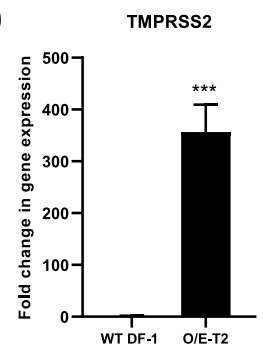

WT DF-1 O/E-T2

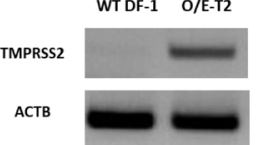

TMPRSS4

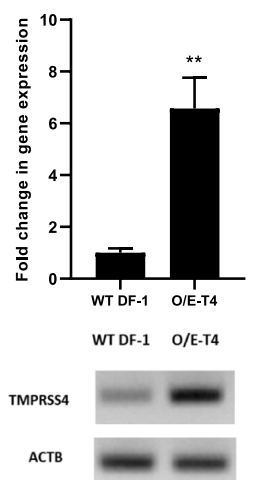

(b)

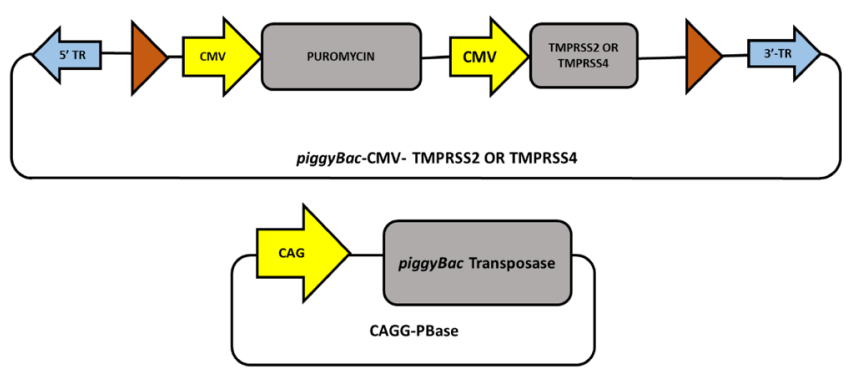

(e)

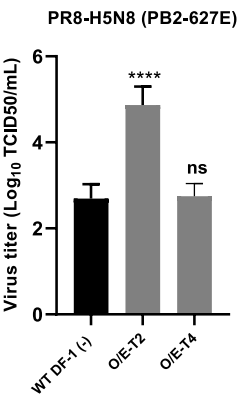

PR8-H9N2 (PB2-627E)

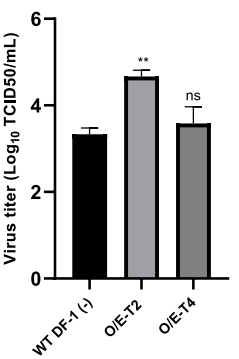

Fig. 1 Establishment of TMPRSS2- and TMPRSS4-overexpressing cell lines and challenge with viruses. a Expression of TMPRSS2 and TMPRSS4 in various chicken tissues and in WT DF-1, as measured by qRT-PCR. Data are normalized to expression of chicken ACTB and are expressed as the mean \pm standard deviation $(n=3)$. Significant differences (compared with WT DF-1 cells) were determined by one-way ANOVA $(* * * * P<0.0001$, ${ }^{*}{ }^{*} P<0.001,{ }^{*} P<0.01$, and $\left.{ }^{*} P<0.05\right)$. $\mathbf{b}$ Schematic representation of the piggyBac transposon based expression vector harboring TMPRSS2 or TMPRSS4. The vector was used to express either TMPRSS2 or TMPRSS4 in WT DF-1 cells, termed O/E-T2 or O/E-T4. c (top) Expression of TMPRSS2 and TMPRSS4 in O/E-T2 and O/E-T4 and in WT DF-1 cells, as measured by qRT-PCR. Data are normalized to expression of chicken ACTB and are expressed as the mean \pm standard deviation $(n=3)$. Significant differences (compared with WT DF-1 cells) were determined by Student's t-test $\left({ }^{* *} P<0.001,{ }^{* *} P<0.01\right.$, and $\left.{ }^{*} P<0.05\right)$. (bottom) Expression of TMPRSS2 and TMPRSS4 in O/E-T2 and O/E-T4 and in WT DF-1 cells, as measured by RT-PCR. The chicken ACTB was used as a reference gene. The full length (uncut) gel electrophoresis image is shown in Additional file 1: Fig. S1. d Cell proliferation at $24 \mathrm{~h}, 48 \mathrm{~h}$, and $72 \mathrm{~h}$ after seeding. Error bars indicate the mean \pm standard deviation of triplicate analyses. e Viral titer of PR8H5N8 (PB2-627E) and PR8-H9N2 (PB2-627E) from O/E-T2 and O/E-T4 relative to that of WT DF-1 cells in the absence of TPCK-trypsin (WT DF-1(-)) at $24 \mathrm{~h}$ post-infection. Significant differences (compared with WT DF-1 cells) were determined by one-way ANOVA $(* * * * P<0.0001$, ns $=$ no significant difference). Data are expressed as the mean \pm standard deviation $(n=7)$

mRNA in O/E-T4 cells was about 6-fold higher than that in WT DF-1. Reverse transcription PCR (RT-PCR) was conducted to further verify the expression of TMPR SS2 and TMPRSS4 (Fig. 1c). To assess whether overexpression of TMPRSS2 and TMPRSS4 had an antagonistic effect on cell proliferation and viability, we conducted a cell proliferation assay. The results showed that proliferation of genetically engineered cells was comparable with that of WT DF-1 cells (Fig. 1d).

Subsequently, we asked whether the proteolytic activity of TMPRSS2 and TMPRSS4 supports viral infectivity and the viral life cycle. Engineered cells were infected with PR8-H5N8 (PB2-627E) and PR8-H9N2 (PB2-627E) [multiplicity of infection $(\mathrm{MOI})=0.1$ ] in the absence of trypsin and the median tissue culture infectious dose $\left(\mathrm{TCID}_{50}\right)$ was calculated to determine the viral titer. Notably, the viral titer in O/E-T2 cells was 35-fold higher when infected with PR8-H5N8 and 23-fold higher when infected with PR8-H9N2 than that in WT DF-1 cells, indicating proteolytic activation of HA by TMPRSS2 and subsequent support of viral replication. Thus, the cell line is suitable for amplification of influenza virus. However, we found no significant difference in the viral titer between O/E-T4 cells overexpressing TMPRSS4 protease and WT-DF1 cells (Fig. 1e) for both strain of viruses.

\section{Establishment of ST3GAL1-overexpressing cells and determination of viral titer}

Sialic acid residues on cell surface receptors are important for binding and endocytosis of influenza virus. Therefore, we examined expression of ST3GAL1 in lung, trachea, liver, small intestine, and large intestine samples from WL chickens and compared it with that by WT DF-1 using qRT-PCR. The results revealed that expression of ST3GAL1 in trachea and lung was significantly higher than that by WT DF-1 cells (Fig. 2a). 
(a)

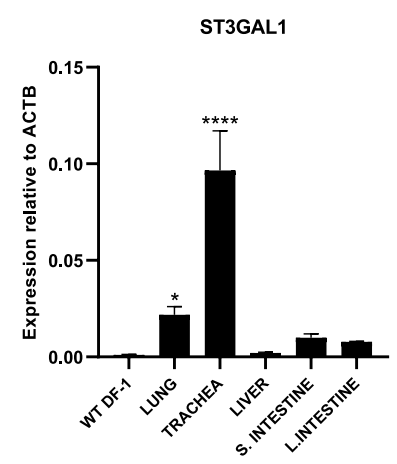

(c)

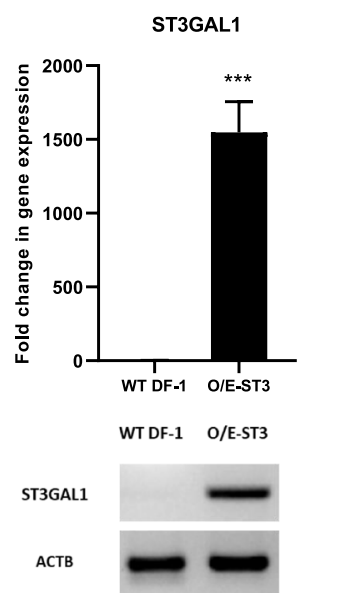

(b)
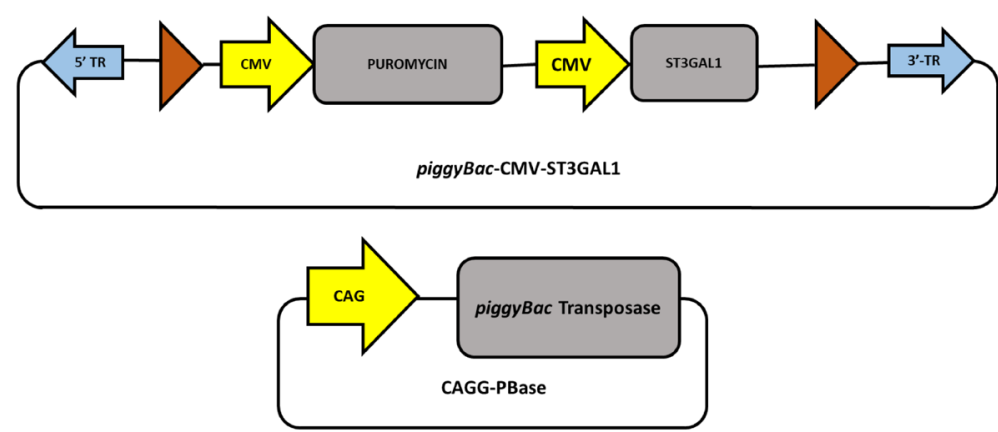

(e)

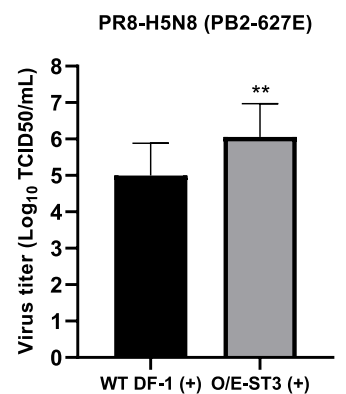

PR8-H9N2 (PB2-627E) (d)

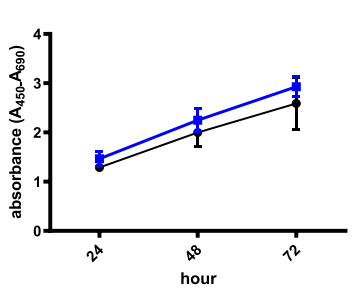

- WT DF-1
$\rightarrow$ OIE-ST3

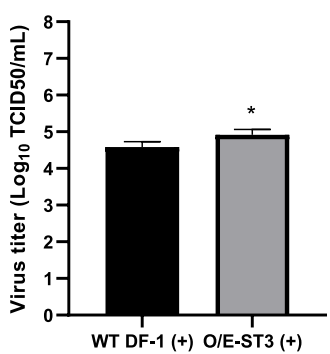

Fig. 2 Establishment of ST3GAL1-overexpressing cell lines and challenge with viruses. a Comparison of ST3GAL1 expression in chicken tissues and WT DF-1 cells by qRT-PCR. Data were normalized to expression of chicken ACTB and are expressed as the mean \pm standard deviation $(n=3)$. Significant differences (compared with WT DF-1 cells) were determined by one-way ANOVA (***P<0.0001, and ${ }^{*} P<0.05$ ). b Schematic representation of the piggyBac transposon based expression vector harboring ST3GAL1. The vector was used to express ST3GAL1 in WT DF-1 cells, termed O/E-ST3. c (top) Expression of ST3GAL1 in O/E-ST3 and WT DF-1 cells, as detected by qRT-PCR. Data were normalized to expression of chicken ACTB and are expressed as the mean \pm standard deviation $(n=3)$. Significant differences (compared with WT DF-1 cells) were determined by Student's t-test ( ${ }^{* *} P<0.001,{ }^{*} P<0.01$, and ${ }^{*} P<0.05$ ) (bottom) Expression of ST3GAL1 in O/E-ST3 and in WT DF-1 cells, as measured by RT-PCR. The chicken ACTB was used as a reference gene. The full length (uncut) gel electrophoresis image is shown in Additional file 2: Fig. S2. d Cell proliferation at $24 \mathrm{~h}, 48 \mathrm{~h}$, and $72 \mathrm{~h}$. Error bars indicate the mean \pm standard deviation of triplicate analyses. e Relative titer of PR8-H5N8 (PB2-627E) or PR8-H9N2 (PB2-627E) after treatment with trypsin (+) in O/E-ST3 cells (O/E-ST3(+)) compared with that in WT DF-1 (WT DF-1(+)) cells treated with trypsin at $24 \mathrm{~h}$ post-infection. Significant differences were determined by Student's t-test $\left({ }^{* *} P<0.01\right.$ and $\left.{ }^{*} P<0.05\right)$. Error bars indicate the mean \pm standard deviation of triplicate analyses

Since WT DF-1 cells expressed lower levels of ST3GAL1, we constructed a piggyBac transposon vector containing the protein coding sequence of chicken ST3GAL1 (Fig. 2b) and transfected it into WT DF-1 to engineer cells that express high levels of ST3GAL1. Subsequently, we analyzed expression of ST3GAL1 in ST3GAL1 overexpressing (O/E-ST3) cells by qRT-PCR. The results showed a 1500-fold increase in expression compared with that in WT DF-1 cells. RT-PCR was conducted to further verify the expression ST3GAL1 (Fig. 2c). To access whether cells overexpressing ST3GAL1 had an antagonistic effect on cell proliferation and viability, we performed a cell proliferation assay. The results revealed that proliferation of genetically engineered cells was comparable with that of WT DF-1 cells (Fig. 2d).
Finally, to examine whether increased expression of ST3GAL1 correlates positively with viral titer, O/E-ST3 cells were infected with PR8-H5N8 (PB2E-627E) or with PR8-H9N2 (PB-627E) at MOI of 0.1 in the presence of trypsin. The $\mathrm{TCID}_{50}$ was calculated to determine the viral titer. The results showed the viral titer in O/E-ST3 cells was significantly higher with both strain of viruses than that in WT DF-1 cells (Fig. 2e).

\section{Establishment of cell lines expressing both ST3GAL1 and TMPRSS2 and their effect on virus titers}

To further investigate whether overexpressing both ST3GAL1 and TMPRSS2 (O/E-ST3T2) generates higher viral titers, we constructed a new piggyBac transposon vector containing the protein coding sequences of ST3GAL1 and TMPRSS2 linked by the self-cleaving 
peptide T2A (Fig. 3a). Cells were transfected with the overexpression vector and analyzed by qRT-PCR. The results showed a 120-fold increase in expression of both ST3GAL1 and TMPRSS2. RT-PCR was conducted to verify the expression of both ST3GAL1 and TMPRSS2 in O/E-ST3T2 (Fig. 3b).

To understand the effect of trypsin on cell viability after infection by influenza virus, we performed a cell proliferation assay. The results revealed a significant difference in viability between WT DF-1(+) and O/EST3T2 cells at $24 \mathrm{~h}$ and $48 \mathrm{~h}$ post-infection, but not at $72 \mathrm{~h}$ post-infection (Fig. 3c) with PR8-H5N8 (PB2-627E). However, with PR8-H9N2 cell viability was very gradual except in WT DF-1 treated with trypsin.

Finally, we examined viral titers at different time points post-infection. Intriguingly, the viral titer in $\mathrm{O} / \mathrm{E}$ ST3T2 cells was significantly higher than that in WT DF-1(+) transfected with empty plasmid control at $72 \mathrm{~h}$ post-infection infected with either PR8-H5N8 (PB2627E) (Fig. 3d) or PR8-H9N2 (PB2-627E) (Fig. 3e). Taken together, the results indicate that engineered $\mathrm{O} /$
E-ST3T2 cells were able to produce high viral titers in the absence of trypsin due to prolonged viability.

\section{Discussion}

Vaccine production in egg-based systems has many disadvantages [12, 13]; therefore, cell-based systems are a suitable alternative. Several cell lines have been established [19] to meet different parameters for virus amplification. However, cell-based systems require addition of exogenous trypsin to support viral replication. Furthermore, developing cell lines from different species is beneficial as it will obviate the need for virus adaptation.

Here, we established chicken DF-1 cells overexpressing chicken protease TMPRSS2; this means that they do not require addition of exogenous trypsin for virus amplification. Consistent with other reports $[1,8,20]$, we found that cells expressing TMPRSS2 supported influenza replication without the need for trypsin. Studies show that HA is cleaved by TMPRSS2 at the plasma membrane during post-translational modification [21]. However, with respect to expression of TMPRSS4, we speculated

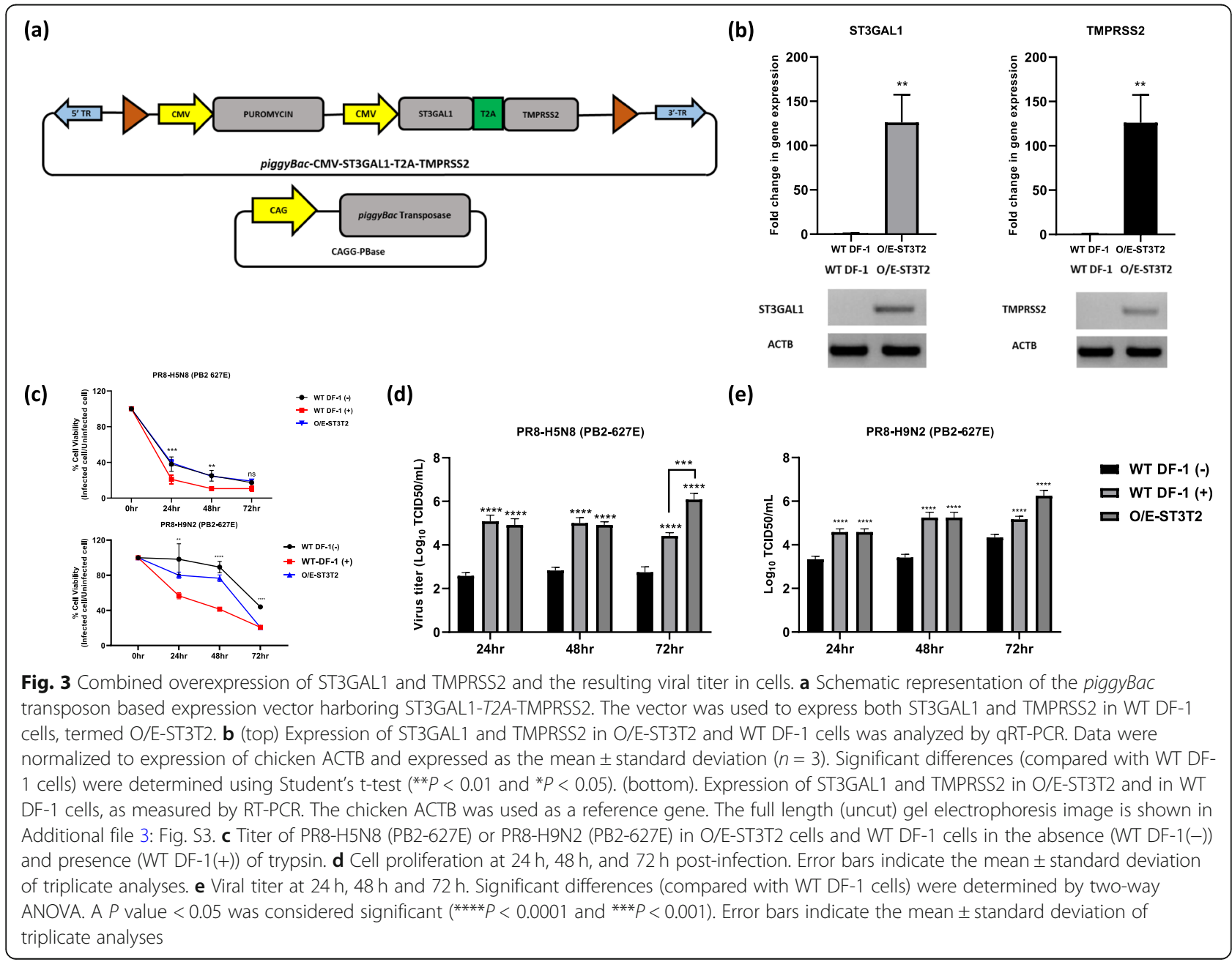


that cells may not support viral replication in the absence of trypsin. Interestingly, overexpression of proteases was not toxic to cells, which grew as well as WT DF-1 cells, even after several serial passages.

Increased expression of sialic acid receptors on the cell surface increases uptake of influenza viruses by cells. Therefore, we engineered cells to overexpress ST3GAL1. These cells generated high virus titers at $24 \mathrm{~h}$ postinfection with the addition of trypsin, suggesting that high expression of $\alpha-2,3$ linked sialic acid residues increased viral uptake. These results are consistent with those of other studies suggesting that abundant expression of sialic acid increases infection of host cells by influenza viruses $[22,23]$.

Finally, we showed that cells overexpressing both ST3GAL1 and TMPRSS2 generated greater viral titers than WT DF-1 cells treated with trypsin. Intriguingly, at $24 \mathrm{~h}$ and $48 \mathrm{~h}$ post-infection, virus titers were comparable with those in WT DF-1 cells treated with trypsin. However, the viability of overexpressing cells was superior at later time points, suggesting that cell viability had an effect on the final viral titers. As expected, viral titers were highest in O/E-ST3T2 cells at $72 \mathrm{~h}$ post-infection; this was most likely due to prolonged viability.

\section{Conclusions}

We showed that genetically engineered chicken DF-1 cells overexpressing both TMPRSS2 and ST3GAL1 support infection and replication of influenza virus in the absence of trypsin. These cell lines could be useful for studying influenza virus replication and host responses in the absence of trypsin, which can degrade interferons secreted by cultured cells [24]. Furthermore, this system can be adapted to amplify influenza for vaccine production because avian-adapted influenza viruses do not require cell adaptation. Collectively, these cell lines can be added to the growing pool of cell-based systems useful for influenza virus amplification.

\section{Methods}

\section{Experimental animals and tissue collection}

The management and experimental use of White Leghorn (WL) chickens and cell lines were approved by the Institutional Animal Care and Use Committee, Seoul National University (SNU-190401-1). The experimental animals were cared for at the University Animal Farm, Seoul National University, in accordance with standard management programs. The chickens used in this study were euthanized by placing in $\mathrm{CO}_{2}$ chamber, then carbon dioxide was filled until the chickens were unconscious and showed no signs of life. After five minutes, the tissue samples from adult WL chicken aged 18 weeks were collected.

\section{Viruses and biosafety}

The PR8-H5N8 (PB2-627E) and PR8-H9N2 (PB2-627E) low pathogenic viruses were generated from eight bidirectional pHW2000 plasmids (a kind gift from Prof. Song Chang Seon of Konkuk University, South Korea) using a reverse genetics system, as previously reported [25]. These viruses are an avian adapted strains (PB2-627E), and therefore, they are suitable to use as the proof of concept. Viruses were rescued by co-transfection of the eight bidirectional plasmids into a co-culture of MDCK cells (MDCK (NBL-2), CCL-34, ATCC) and human 293 T embryonic kidney cells (293 T, CRL-11268, ATCC). Generated viruses were grown in MDCK infection medium comprising Dulbecco's Modified Eagle's Medium (DMEM) (Hyclone, Logan, UT, USA) supplemented with $0.3 \%$ bovine serum albumin (BSA), $1 \times$ antibiotic antimycotic (ABAM), and $1 \mu \mathrm{g} / \mathrm{ml} \mathrm{L}$-(tosylamido-2-phenyl) ethyl chloromethyl ketone (TPCK)treated trypsin (Sigma-Aldrich, MO, USA), and then incubated at $37^{\circ} \mathrm{C}$ for $48 \mathrm{~h}$. Virus stocks were further propagated in 10-day-old embryonated chicken eggs. Aliquots of infectious virus were stored at $-80^{\circ} \mathrm{C}$ until required. All work with low pathogenicity viruses was conducted in a biosafety level 2 facility approved by the Institutional Biosafety Committee of Seoul National University.

\section{Construction of overexpression plasmids}

The piggyBac plasmid (Addgene plasmid no. 92078, Addgene, MA, USA) containing enhanced green fluorescent protein (eGFP) was digested with AgeI and BsrGI enzymes to create a linearized vector. A synthetic protein coding region of chicken TMPRSS2 (NCBI Gene ID 418528), chicken TMPRSS4 (NCBI Gene ID 770454), chicken ST3GAL1 (NCBI Gene ID 396140), or chicken ST3GAL1-T2A-TMPRSS2 (Bionics, Korea) was cloned into the linearized vector using Takara In-Fusion Ligation mix (Takara, Kasatsu, Japan), according to the manufacturer's protocol. The resulting plasmid was amplified and purified using a Plasmid Maxi kit (Qiagen, Hilden, Germany). The correct insert was confirmed by sequencing.

\section{Cell culture and establishment of overexpressing DF-1 cell lines}

Chicken DF-1 fibroblast cells (UMNSAH/DF-1, CRL12203, ATCC) were maintained in high glucose DMEM supplemented with $10 \%$ fetal bovine serum (Hyclone) and $1 \times$ ABAM. Cells were maintained at $37^{\circ} \mathrm{C}$ at $5 \%$ $\mathrm{CO}_{2}$ under $60-70 \%$ relative humidity. To establish cell lines that stably overexpress the genes of interest, $1.2 \mu \mathrm{g}$ of overexpression vector and $0.8 \mu \mathrm{g}$ of piggyBac transposon (pCyL50) were transfected into DF-1 cells using Lipofectamine 2000 (Thermo Fisher Scientific, Waltham, 
MA, USA). After $6 \mathrm{~h}$, transfection mixtures were replaced with DF-1 culture medium supplemented with puromycin (Thermo Fisher Scientific). Cells were maintained in culture medium supplemented with puromycin for 1 week to recover overexpressing cells. The cell lines were maintained for more than 15 passages for subsequent analysis.

\section{RNA isolation, qRT-PCR and RT-PCR analysis}

Total RNA from cells or tissues was extracted using Trireagent (Molecular Research Center Inc., Cincinnati, Ohio, USA). RNA quantity was determined by spectrophotometry at $260 \mathrm{~nm}$, and $0.5-1 \mu \mathrm{g}$ of each sample was reverse-transcribed using the Superscript IV First-Strand Synthesis System (Thermo Fisher Scientific). The complementary DNA (cDNA) was diluted five-fold and the concentrations standardized for amplification by PCR. qRT-PCR was conducted to examine changes in expression of candidate genes in test samples and in overexpressing DF-1 cells. The PCR reaction mixture contained $2 \mu \mathrm{l}$ of PCR buffer, $1 \mu \mathrm{l}$ of $20 \times$ EvaGreen qPCR dye (Biotium, Hayward, CA, USA), $0.5 \mu \mathrm{l}$ of 10 $\mathrm{mM}$ dNTP mixture, 10 pmole each of target genespecific forward and reverse primers (Table 1), $1 \mu \mathrm{l}$ of cDNA, and $1 \mathrm{U}$ of Taq DNA polymerase (final volume, $20 \mu \mathrm{l})$. qRT-PCR was conducted in a StepOnePlus realtime PCR system (Applied Biosystems, CA, USA). Each test sample was assayed in triplicate. Relative quantification of target gene expression in the cells was performed using the following formulae: $2^{-\Delta \mathrm{Ct}}$, where $\Delta \mathrm{Ct}=(\mathrm{Ct}$ of the target gene-Ct of $A C T B)$, or $2^{-\Delta \Delta \mathrm{Ct}}$, where $\Delta \Delta \mathrm{Ct}=$ (Ct of the target gene-Ct of $A C T B)$ group-(Ct of the target gene-Ct of ACTB) control. RT-PCR was conducted to examine changes in expression of candidate genes in test samples and in overexpressing DF-1 cells. The PCR reaction mixture contained $2 \mu \mathrm{l}$ of PCR buffer, $0.5 \mu \mathrm{l}$ of $10 \mathrm{mM}$ dNTP mixture, 10 pmole each of target gene-specific forward and reverse primers (Table 1), $1 \mu \mathrm{l}$ of cDNA, and $1 \mathrm{U}$ of Taq DNA polymerase (final volume, $20 \mu \mathrm{l})$. RT-PCR was performed using T100 Thermal Cycler (Bio-Rad, Hercules, CA, USA), and the

Table 1 List of primers used for qRT-PCR and RT-PCR

\begin{tabular}{ll}
\hline ID & Sequence $\left(\mathbf{5}^{\prime} \boldsymbol{\rightarrow} \mathbf{3} \mathbf{)}\right.$ \\
\hline ACTB - F & AGGAGATCACAGCCCTGGCA \\
ACTB - R & CAATGGAGGGTCCGGATTCA \\
ST3GAL1 - F & CACCCACCATTGGCTACGAA \\
ST3GAL1 - R & AGGCCTGTGGAAGGGTATCT \\
TMPRSS2 - F & TTCTGCCAGGCCACAAGTAG \\
TMPRSS2 - R & GGAGAAATGCACACTCCCGA \\
TMPRSS4 - F & TCCCCTCTGGATCCTCACTG \\
TMPRSS4 - R & TCCAGCTCCTCGTCGAAGTA \\
\hline
\end{tabular}

products were separated by gel electrophoresis and visualized using the Gel Doc XR+ Imaging System (BioRad). The chicken ACTB was used as a reference gene.

\section{Viral infection of cells}

The O/E-ST3, O/E-T2, O/E-ST3T2, or WT DF-1 cells were seeded on 12-well plates and grown to confluence. The culture medium was removed and the cells were washed twice with PBS prior to incubation at $37^{\circ} \mathrm{C}$ for 20 min in DMEM containing 1\% penicillin/streptomycin. Next, DMEM containing $1 \%$ penicillin/streptomycin containing PR8-H5N8 (PB2-627E) or with PR8-H9N2 (PB2-627E) virus at a multiplicity of infection (MOI) of 0.1 or 0.01 was added for 50 min. Finally, cells were washed with PBS, and incubated with DMEM containing $1 \%$ penicillin/streptomycin for $24 \mathrm{~h}, 48 \mathrm{~h}$, and $72 \mathrm{~h}$ until harvesting the medium for viral titration as stated below.

\section{WST-1 assay of overexpressing cells and virus-infected cells}

The Premix WST-1 Cell Proliferation Assay System (Takara Bio, Kusatsu, Japan) was used to measure cell proliferation. Briefly, cells $\left(0.15 \times 10^{4}\right.$ cells per well $)$ were seeded in a 96-well plate in which each well contained $0.1 \mathrm{ml}$ of culture medium. At $2 \mathrm{~h}$ before each time point $(24 \mathrm{~h}, 48 \mathrm{~h}$ and $72 \mathrm{~h}$ ) post-seeding, $10 \mu \mathrm{l}$ of WST-1 Premix solution was added to the cells and incubated at $37^{\circ} \mathrm{C}$. Next, optical density was measured at an absorbance of 450 and $690 \mathrm{~nm}$ (A450-A690). Data were analyzed to determine proliferation and viability. Similarly, infected O/E-ST3, O/E-T2, and O/E-ST3T2 cells $(1 \times$ $10^{4}$ cells per well) were seeded in a 96-well plate in which each well contained $0.1 \mathrm{ml}$ of culture medium. One day later, confluent DF-1 cells were infected with PR8-H5N8 (PB2-627E) or with PR8-H9N2 (PB2-627E) at a MOI of 0.1. Percentage survival was calculated as the ratio of the optical absorbance at 450 and $690 \mathrm{~nm}$ (A450-A690) of infected DF-1 cells and non-infected control DF-1 cells. All experiments were performed in triplicate, with three independent samples.

\section{Viral titration}

The virus titer in infected O/E-ST3, O/E-T2, O/EST3T2 DF-1 cells, or WT DF-1 cells was determined by calculating the median tissue culture infectious dose $\left(\mathrm{TCID}_{50}\right)$. MDCK cells were cultured in Eagle's Minimum Essential Medium (EMEM) (ATCC, Manassas, VA, USA) supplemented with $10 \%$ fetal bovine serum (Hyclone) and 1x ABAM. For viral titration, MDCK cells $\left(2.5 \times 10^{4}\right.$ cells per well $)$ were seeded in 96 -well plates until confluence in culture media and subsequently confluent layer of MDCK cells were wash with PBS and treated with DMEM supplemented with $1 \%$ penicillin/ 
streptomycin and infected with PR8-H5N8 (PB2-627E) or with PR8 H9N2 (PB2-627E) from the O/E-ST3, O/ET2, O/E-ST3T2 DF-1 cells, or WT DF-1 cells for $50 \mathrm{~min}$ at $37^{\circ} \mathrm{C}$. Then, the MDCK cells was washed with PBS, and finally incubated with DMEM supplemented with $0.3 \%$ BSA, $1 \%$ penicillin/streptomycin, and $1 \mu \mathrm{g} / \mathrm{ml}$ TPCK-trypsin at $37^{\circ} \mathrm{C}$. After $72-96 \mathrm{~h}$, the plate was stained with crystal violet (Sigma-Aldrich) to observe cytopathic effects. The $\mathrm{TCID}_{50}$ values per milliliter were calculated using the Spearman-Karber formula [26].

\section{Statistical analysis}

Statistical analysis was performed using GraphPad Prism software (GraphPad Software 8, San Diego, CA). Significant differences between two groups were determined using Student's t-test. Significant differences between groups were determined using ANOVA with Bonferroni's multiple comparison. A $P$ value $<0.05$ was considered significant $\left({ }^{* * * * *} P<0.0001,{ }^{* * * *} P<0.001\right.$, ${ }^{* * *} P<0.01$, and $\left.{ }^{*} P<0.05\right)$.

\section{Supplementary Information}

The online version contains supplementary material available at https://doi. org/10.1186/s12896-020-00663-6

Additional file 1: Figure S1. The full length (uncut) gel electrophoresis image of Fig. 1C.

Additional file 2: Figure S2. The full length (uncut) gel electrophoresis image of Fig. 2C.

Additional file 3: Figure S3. The full length (uncut) gel electrophoresis image of Fig. 3b.

\section{Abbreviations}

HA: Hemagglutinin; HAT: Human airway trypsin-like protease; HPAIV: High pathogenic avian influenza virus; LPAIV: Low pathogenic avian influenza virus; MDCK: Madin-darby canine kidney; ST3GAL1: ST3 beta-galactoside alpha-2,3-sialyltransferase 1; TMPRSS2: Transmembrane serine protease 2; TMPRSS4: Transmembrane serine protease 4; O/E-ST3: Overexpression of ST3 beta-galactoside alpha-2,3-sialyltransferase 1; O/E-ST3T2: Overexpression of both ST3 beta-galactoside alpha-2,3-sialyltransferase 1 and transmembrane serine protease 2; O/E-T2: Overexpression of transmembrane serine protease 2; O/E-T4: Overexpression of transmembrane serine protease 4; vRNA: Viral ribonucleic acid

\section{Acknowledgments}

Not applicable.

\section{Authors' contributions}

$\mathrm{KC}, \mathrm{YH}$, and JY conceived and designed the experiment. KC, SJ, and SB performed the experiments. $\mathrm{KC}, \mathrm{YH}$ and $J \mathrm{Y}$ analyzed the data. $\mathrm{KC}$ wrote the first draft manuscript. KC, YH, DR, HJ and JY wrote the final manuscript. All authors read and approved the final manuscript.

\section{Funding}

This work was supported by the National Research Foundation of Korea (NRF) grant funded by the Korea government (MSIP) (No.

2015R1A3A2033826), and the Next-Generation BioGreen 21 Program (Project No. PJ01316401), Rural Development Administration, Republic of Korea.

\section{Availability of data and materials}

The datasets used and/or analyzed during the current study are available from the corresponding author on reasonable request.

\section{Ethics approval and consent to participate}

The management and experimental use of White Leghorn (WL) chickens and cell lines were approved by the Institutional Animal Care and Use Committee, Seoul National University.

\section{Consent for publication}

Not applicable.

\section{Competing interests}

All authors reported no competing interests.

Received: 26 February 2020 Accepted: 18 December 2020

Published online: 07 January 2021

\section{References}

1. Böttcher E, Freuer C, Steinmetzer T, Klenk H-D, Garten W. MDCK cells that express proteases TMPRSS2 and HAT provide a cell system to propagate influenza viruses in the absence of trypsin and to study cleavage of $\mathrm{HA}$ and its inhibition. Vaccine. 2009;27(45):6324-9.

2. Galloway SE, Reed ML, Russell CJ, Steinhauer DA. Influenza HA subtypes demonstrate divergent phenotypes for cleavage activation and $\mathrm{pH}$ of fusion: implications for host range and adaptation. PLoS Pathog. 2013;9(2): e1003151.

3. Russell CJ, Hu M, Okda FA. Influenza hemagglutinin protein stability, activation, and pandemic risk. Trends Microbiol. 2018;26(10):841-53.

4. Luczo JM, Tachedjian M, Harper JA, Payne JS, Butler JM, Sapats SI, et al. Evolution of high pathogenicity of $\mathrm{H} 5$ avian influenza virus: haemagglutinin cleavage site selection of reverse-genetics mutants during passage in chickens. Sci Rep. 2018:8(1):11518.

5. Horimoto T, Nakayama K, Smeekens SP, Kawaoka Y. Proprotein-processing endoproteases PC6 and furin both activate hemagglutinin of virulent avian influenza viruses. J Virol. 1994;68(9):6074-8.

6. Stieneke-Gröber A, Vey M, Angliker H, Shaw E, Thomas G, Roberts $\mathrm{C}$, et al. Influenza virus hemagglutinin with multibasic cleavage site is activated by furin, a subtilisin-like endoprotease. EMBO J. 1992:11(7):2407-14.

7. Walker JA, Molloy SS, Thomas G, Sakaguchi T, Yoshida T, Chambers TM, et al. Sequence specificity of furin, a proprotein-processing endoprotease, for the hemagglutinin of a virulent avian influenza virus. J Virol. 1994;68(2): 1213-8.

8. Baron J, Tarnow C, Mayoli-Nüssle D, Schilling E, Meyer D, Hammami M, et al. Matriptase, HAT, and TMPRSS2 activate the hemagglutinin of H9N2 influenza a viruses. J Virol. 2013:87(3):1811-20.

9. Bertram S, Glowacka I, Blazejewska P, Soilleux E, Allen P, Danisch S, et al. TMPRSS2 and TMPRSS4 facilitate trypsin-independent spread of influenza virus in Caco-2 cells. J Virol. 2010;84(19):10016-25.

10. Böttcher-Friebertshäuser E, Klenk H-D, Garten W. Activation of influenza viruses by proteases from host cells and bacteria in the human airway epithelium. Pathog Dis. 2013:69(2):87-100.

11. Wen Z, Wu C, Chen W, Zeng X, Shi J, Ge J, et al. Establishment of MDCK stable cell lines expressing TMPRSS2 and MSPL and their applications in propagating influenza vaccine viruses in absence of exogenous trypsin. Biotechnol Res Int. 2015;2015:402628.

12. Wu NC, Lv H, Thompson AJ, Wu DC, Ng WW, Kadam RU, et al. Preventing an antigenically disruptive mutation in egg-based H3N2 seasonal influenza vaccines by mutational incompatibility. Cell Host Microbe. 2019;25(6):836844.e5.

13. Audsley JM, Tannock GA. Cell-based influenza vaccines. Drugs. 2008;68(11): 1483-91.

14. Soema PC, Kompier R, Amorij J-P, Kersten GF. Current and next generation influenza vaccines: formulation and production strategies. Eur J Pharm Biopharm. 2015;94:251-63.

15. Klenk H-D, Rott R, Orlich M, Blödorn J. Activation of influenza a viruses by trypsin treatment. Virology. 1975;68(2):426-39.

16. Le Ru A, Jacob D, Transfiguracion J, Ansorge S, Henry O, Kamen AA Scalable production of influenza virus in HEK-293 cells for efficient vaccine manufacturing. Vaccine. 2010;28(21):3661-71.

17. Kim E-H, Kwon H-I, Park S-J, Kim Y-I, Si Y-J, Lee I-W, et al. Generation of a high-growth influenza vaccine strain in MDCK cells for vaccine preparedness. J Microbiol Biotechnol. 2018;28(6):997-1006. 
18. Lee C-W, Jung K, Jadhao S, Suarez D. Evaluation of chicken-origin (DF-1) and quail-origin (QT-6) fibroblast cell lines for replication of avian influenza viruses. J Virol Methods. 2008;153(1):22-8.

19. Petiot E, Proust A, Traversier A, Durous L, Dappozze F, Gras M, et al.

Influenza viruses production: evaluation of a novel avian cell line DuckCelt ${ }^{\oplus}$ T17. Vaccine. 2018;36(22):3101-11.

20. Limburg H, Harbig A, Bestle D, Stein DA, Moulton HM, Jaeger J, et al. TMPR SS2 is the major activating protease of influenza a virus in primary human airway cells and influenza B virus in human type II pneumocytes. J Virol. 2019;93(21):e00649-19.

21. Böttcher-Friebertshäuser E, Freuer C, Sielaff F, Schmidt S, Eickmann M, Uhlendorff J, et al. Cleavage of influenza virus hemagglutinin by airway proteases TMPRSS2 and HAT differs in subcellular localization and susceptibility to protease inhibitors. J Virol. 2010;84(11):5605-14.

22. Kimble B, Nieto GR, Perez DR. Characterization of influenza virus sialic acid receptors in minor poultry species. Virol J. 2010;7(1):365.

23. van Riel D, Munster VJ, de Wit E, Rimmelzwaan GF, Fouchier RA, Osterhaus $A D$, et al. Human and avian influenza viruses target different cells in the lower respiratory tract of humans and other mammals. Am J Pathol. 2007: 171(4):1215-23.

24. Seitz C, Isken B, Heynisch B, Rettkowski M, Frensing T, Reichl U. Trypsin promotes efficient influenza vaccine production in MDCK cells by interfering with the antiviral host response. Appl Microbiol Biotechnol. 2012; 93(2):601-11.

25. Park YH, Chungu K, Lee SB, Woo SJ, Cho HY, Lee HJ, et al. Host-specific restriction of avian influenza virus caused by differential dynamics of ANP32 family members. J Infect Dis. 2019;221(1):71-80.

26. Gilles H. Calculation of the index of acute toxicity by the method of linear regression. Comparison with the method of" Karber and Behrens". Eur J Toxicol Environ Hyg. 1974;7(2):77-84.

\section{Publisher's Note}

Springer Nature remains neutral with regard to jurisdictional claims in published maps and institutional affiliations.

Ready to submit your research? Choose BMC and benefit from:

- fast, convenient online submission

- thorough peer review by experienced researchers in your field

- rapid publication on acceptance

- support for research data, including large and complex data types

- gold Open Access which fosters wider collaboration and increased citations

- maximum visibility for your research: over $100 \mathrm{M}$ website views per year

At $\mathrm{BMC}$, research is always in progress.

Learn more biomedcentral.com/submissions 